УдК: 331.108

ИБРАГИМОВА ПАИЗАТ АЛИЕВНА

к.э.н., доцент кафедры «Аудит и экономический анализ» ФБГБОУ ВО «Дагестанский государственный университет», e-mail: paizat_i@mail.ru

ГУСАЙНИЕВА ХАМИС ГУСАЙНИЕВНА

студент ФОГБОУ ВО «Дагестанский государственный университет», e-mail: gusaynieva2000@mail.ru

DOI:10.26726/1812-7096-2021-5-127-133

\title{
КААРОВАЯ БЕЗОПАСНОСТЬ: РИСКИ, УГРОЗЫ, ПУТИ СОВЕРШЕНСТВОВАНИЯ
}

\begin{abstract}
Аннотауия. Данная статья раскрывает проблемы преодоления рисков и угроз кадровой безопасности. Обобщены теоретические подходы к понятиям «кадровая безопасность», «кадровые риски», «угрозы кадровой безопасности». В проиессе подготовки, сбора и обобщения результатов были применены общенаучные методы исследования. Наличие кадровых угроз определяется угрозой кадровой безопасности субъект-объектных отношений. Сотрудники предприятий могут быть как субъектом, так и объектом угроз, что, в свою очередь, говорит о том, что угрозы кадровой безопасности носят двойственный характер. При этом угрозой кадровой безопасности подвергаются не только работники компании, но и претенденты на вакантную должность, а также бывшие сотрудники. Также отмечается, что в условиях пандемии в эффективной системе кадровой безопасности фирмы нуждаются особенно остро. Полученные результаты позволяют констатировать, что для обеспечения эффективной кадровой безопасности в любом современном предприятии должны приниматься и осуществляться различные меры в сфере управления персоналом, направленные на сокращение риска нанесения ущерба организащией персоналом и непосредственно самому персоналу.
\end{abstract}

Ключевые слова: кадровая безопасность, кадровый риск, кадровая угроза, пандемия, персонал.

IBRAGIMOVA PAIZAT ALIEVNA

Ph. D. in Economics, Associate Professor of the Department

" Audit and Economic Analysis» Dagestan State University, e-mail: paizat_i@mail.ru

GUSAINIEVA KHAMIS GUSAINIEVNA

Student of Dagestan State University, e-mail: gusaynieva2000@mail.ru

\section{PERSONNEL SECURITY: RISKS, THREATS, WAYS OF IMPROVEMENT}

Abstract. This article reveals the problems of overcoming risks and threats to personnel security.

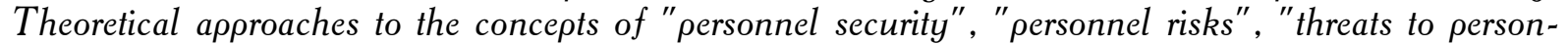
nel security"are summarized. In the process of preparing, collecting and summarizing the results, general scientific research methods were applied. The presence of personnel threats is determined by the threat to the personnel security of the subject-object relations. Employees of enterprises can be both the subject and the object of threats, which, in turn, suggests that threats to personnel security are of a dual nature. At the same time, not only employees of the company, but also applicants for a vacant position, as well as former employees, are exposed to the threat of personnel security. It is also noted that in the conditions of a pandemic, firms need an effective personnel security system especially acutely. The results obtained allow us to state that in order to ensure effective personnel security in any modern enterprise, various measures in the field of personnel management should be taken and implemented, aimed at reducing the risk of damage to the organization by personnel and directly to the personnel themselves.

Keywords: personnel security, personnel risk, personnel threat, pandemic, personnel. 
1. Введение. В нынешнее время, когда для осуществления своей деятельности каждое предприятие стремится преодолеть кризисные ситуации и получить максимальную прибыль, необходимым условием для эффективности деятельности выступает кадровая безопасность. В современных условиях повышение уровня конкурентоспособности предприятия определяется наличием квалифицированного и компетентного персонала, оптимальным подбором и расстановкой кадров. Каждой организации важно стремиться не сколько взаимодействовать со всеми заинтересованными сторонами на рынке предоставляемых услуг и товаров, сколько сохранять свою уникальность и целостность. Фурсов В.А., Лазарева Н.В., Кущ Е.Н., Аветова К.Г. отмечают, что «... грамотно подобранная система деятельности служб кадровой безопасности организации, которая будет способна вовремя распознать и противостоять различным угрозам, необходима для достижения намеченных планов и бизнес-идей» [11]. И именно поэтому обеспечение кадровой безопасности является направлением работы любой современной организации.

\section{2. Основная часть.}

2.1 Подходы к определению кадровой безопасности и ее сущности

Анализ теоретических подходов к понятию и сущности кадровой безопасности дал понять, что эта разновидность безопасности может быть рассмотрена с различных позиций. С одной стороны, кадровая безопасность представляет собой процесс, обеспечивающий текущую и перспективную защиту персонала организации от различных опасных ситуаций во время отбора и адаптации персонала, совершенствования и повышения квалификационных качеств сотрудников, при перемещении и увольнении из организации. В таком случае в качестве источника возникновения таких угроз и опасностей выступает руководитель, нарушающий права своих подчинённых.

С другой стороны, кадровая безопасность выступает в качестве способа активной защиты, в которой уже нуждается сама фирма. В частности, рассматриваются вопросы, связанные с экономической безопасностью, имиджем и стабильным ходом бизнес-процессов во внутренней среде, а также опасностью, которая возникает в результате осознанных либо неосознанных действий работников организации [3]. Так, работники могут вступить в сговор, передать конфиденциальные сведения третьим лицам или конкурентам либо же использовать эти данные в других целях.

Безопасность сотрудников в каждой организации должна иметь наивысший приоритет в сравнении с остальными направлениями деятельности, минимизирующими риски предприятия (финансовые, юридические, информационные, технологические и др.). Человеческий фактор всегда важнее, поскольку сами люди как создают, так и предотвращают угрозы безопасности организаций [7].

Кадровая безопасность может быть рассмотрена с точки зрения различных подходов

\begin{tabular}{|c|l|}
\hline \multicolumn{1}{|c|}{ Подходы } & \multicolumn{1}{|c|}{ Определение } \\
\hline Функциональный & $\begin{array}{l}\text { Кадровая безопасность представляет собой генеральное направление кадровой работы, сово- } \\
\text { купность принципов, методов, форм организационного механизма по формулированию целей, } \\
\text { ответственного и высокопроизводительного, сплоченного коллектива, способного своевремен- } \\
\text { оо реагировать на непрерывно меняющиеся требования рынка с учетом стратегии развития } \\
\text { фирмы. }\end{array}$ \\
\hline Процессный & $\begin{array}{l}\text { Кадровая безопасность выступает в качестве процесса, предотвращающего отрицательные воз- } \\
\text { действия на экономическую безопасность организации за счет рисков и угроз, связанных с пер- } \\
\text { соналом, его интеллектуальным потенциалом и трудовыми отношениями в целом. }\end{array}$ \\
\hline Целевой & $\begin{array}{l}\text { Кадровая безопасность представляет собой такое состояние защищенности организации от кад- } \\
\text { ровых рисков и угроз, механизмом обеспечения которого является эффективное управление } \\
\text { сотрудниками. }\end{array}$ \\
\hline Структурный & $\begin{array}{l}\text { Кадровая безопасность выступает как один из элементов комплексной экономической безопас- } \\
\text { ности фирмы, которая имеет в качестве приоритета защиту от угроз и рисков с целью повыше- } \\
\text { ния эффективности управления кадрами, поскольку последние являются важнейшим ресурсом, } \\
\text { обесечивающим высокий уровень конкурентоспособности фирмы. }\end{array}$ \\
\hline
\end{tabular}

Сущность системы кадровой безопасности состоит в том, что она основывается на трёх важных аспектах: эффективном поиске и подборе сотрудников, надёжности и преданности 
штата, контроле кадров. Как и любая другая система, кадровая безопасность имеет свои субъекты и объекты. Так, субъектами являются топ-менеджеры, работники подразделения по управлению кадрами, работники, занятые в сфере корпоративной безопасности, а также работники, имеющие доступ к различным ресурсам, прочий персонал. Объектами, в свою очередь, могут выступать все работники организации [2].

\section{2 Кадровый риск: сущность и классификация}

При рассмотрении сущности кадровой безопасности необходимо изучить и такие понятия, как «кадровые риски» и «угрозы кадровой безопасности».

Кадровый риск представляет собой риск возможной потери ресурсов предприятия или потери прибыли вследствие допущения различного рода ошибок и просчетов в управлении персоналом по сравнению с планируемыми данными, исчисленными при условии рационального и эффективного использования человеческих ресурсов [1].

Как показали исследования в отношении риска, больше всего анализируют риски, образованные в разных областях деятельности фирм, в то время как рискам, порождающимся в работе с кадрами, уделяют намного меньше внимания, хотя, как известно, и сейчас очень большое число предприятий заинтересовано в поиске и найме квалифицированных и компетентных специалистов, коих на рынке труда не так уж и много.

Существует удобная и очень подробная классификация кадровых рисков, созданная Т.О. Соломанидиной, учитывающая довольно много вероятных аспектов [10]:

1) по возможности прогнозирования и точности оценки: прогнозируемые, трудно прогнозируемые, непрогнозируемые;

2) по калькулируемости: калькулируемые, некалькулируемые;

3) по уровню управляемости: управляемые, условно-нерегулируемые, неуправляемые;

4) по характеру вероятных потерь: материальные, трудовые, финансовые, потери времени, специальные;

5) по разновидности ущерба от риска: прямые потери, косвенные потери;

6) риски, возникающие на различных этапах работы с сотрудниками: поиска и подбора, адаптации, обучения и повышения квалификации, мотивации, оценки, контроля, увольнения;

7) по характеру расходов по рискам: при принятии решения условий рисков, при минимизации рисков, при ликвидации последствий появления рисков;

8) по природе возникновения: объективные, субъективные;

9) по источникам возникновения риска: экономические, политические, технические, экологические, социальные, юридические, информационные;

10) по намеренности возникновения: случайные, неслучайные;

11) по причине возникновения: риски нелояльности, риски взаимодействия работников, риски нехватки данных, риски непрофессионализма управляющего отделом кадров, риски, связанные с лидером, риски, исходящие от конкурентов;

12) по месту возникновения: внешние, внутренние;

13) по степени обоснованности риска: обоснованные, необоснованные;

14) по степени допустимости: минимальные, допустимые, критические, катастрофические;

15) по возможности страхования: страхуемые и нестрахуемые.

Данная классификация может быть расширена за счёт включения в неё дополнительных оснований:

1) по отраслевой принадлежности: риски, возникающие только в отдельных отраслях; риски, возникающие во всех отраслях;

2) по значимости для фирмы: имеющие особую важность, неприоритетные;

3) по степени правомерности: оправданные, неоправданные.

Также говоря о рисках, нельзя не упомянуть категорию рисков, непосредственно касающихся управления, так как, как правило, довольно часто работодатели заняты поиском источников возникновения угроз только среди своих подчинённых, забывая об управленческом аппарате, в который они входят сами. Так, среди управленческих рисков необходимо отметить следующие:

1) возникающие вследствие неэффективных либо малоэффективных управленческих решений; 
2) возникающие вследствие нерезультативного механизма реализации управленческих решений;

3) риски информации;

4) риски коммуникации [4].

\section{3 Анализ угроз кадровой безопасности, меры по их минимизации}

Что касается угроз безопасности организации, связанных с управлением кадрами, то они возникают уже после реализации риска и могут привести к потерям для предприятия в разных направлениях: ущерб деловой репутации фирмы на рынке, материальные (денежные) потери и т.д. Важной отличительной чертой угроз кадровой безопасности выступает их персонифицированность.

Согласно постулатам антропологической концепции безопасности, в качестве субъекта угрозы кадровой безопасности выступает сам человек. Причём угрожать могут не только действующие работники предприятия, но и претендующие на вакантное место, а также уволенные работники, затаившие обиду и жаждущие мести [5].

Объектом угрозы кадровой безопасности служат различные ресурсы: финансовые, материальные, информационные, трудовые и т.д. [8]. Из чего следует, в качестве объекта угроз могут выступать люди. Таким образом, можем сделать вывод о том, что работники могут быть как субъектом, так и объектом угроз, что, в свою очередь, говорит о том, что угрозы кадровой безопасности носят двойственный характер [9].

В этой связи подразумевается, что «кадровые угрозы» тоже имеют два направления:

1) деятельность уволенных работников, уже работающих кадров и претендентов, которая представляет риски для всего предприятия, его отдельных подразделений и направлений;

2) риск (физический, медицинский, психологический, репутационный, финансовый и т.д.) со стороны сотрудников фирмы, образованный вследствие деятельности отдельных лиц и социальных групп, государственных и общественных институтов, неблагоприятного воздействия природных и антропогенных сил.

Уволенный работник мог испытывать чувство обиды, злости и желания отомстить и, как следствие, совершить определенные действия, которые могут негативно повлиять на репутацию предприятия, его имиджа и т.п. Так, в качестве таких действий может быть оспаривание этим бывшим работником решения работодателя по поводу своего увольнения в суде, нанесение физического воздействия лицам, которых он считает виноватыми, сокрытие или уничтожение важных документов, передача конфиденциальных сведений фирме-конкуренту и т.д. [6].

Претенденты на вакантные места могут оказаться ложными и быть подосланы со стороны конкурентов в целях кражи секретных данных и передачи их тем, чьи интересы они представляют, либо же использования в своих личных корыстных целях [12]. Нынешние работники фирмы также могут представлять собой угрозу кадровой безопасности.

Бывает и такое, что осуществление угроз безопасности со стороны сотрудников, согласно требованиям российского законодательства, может быть классифицировано как преступление. И, согласно предписаниям Уголовного кодекса Российской Федерации, такими преступлениями могут быть кража (ст. 158 УК РФ), мошенничество (ст.159 УК РФ), хищение чужого имущества, вверенного виновному (ст. 160 УК РФ), причинение материального ущерба путем обмана или злоупотребления доверием (ст. 165 УК РФ), злоупотребление служебным положением (ст. 285 УК РФ), коммерческий подкуп (ст. 204 УК РФ), незаконное получение и разглашение сведений, составляющих коммерческую и иную тайну (ст. 183 УК РФ) и т.д. [5].

Обеспечение кадровой безопасности компании связано с нейтрализацией кадровых угроз персоналу.

Основными причинами, провоцирующими деструктивные действия со стороны сотрудников в отношении предприятия, являются следующие:

1) низкий уровень либо же полное отсутствие корпоративной социальной ответственности, проявляющееся в недовыполнении фирмой своих обязательств перед работниками;

2) неграмотная политика увольнений;

3) отсутствие эффективной системы стимулирования кадров [13]. 
Для того чтобы нейтрализовать кадровые угрозы на предприятии, необходимо принимать меры по двум основным направлениям. Первое направление заключается в предотвращении угроз за счёт осуществления качественного поиска и подбора штата и образования эффективной системы защиты сотрудников. Методика поиска и подбора претендентов на вакантные места при устройстве работника на должность не должна учитывать различные личные сведения кандидатов, не имеющие отношения к будущей работе и делающие их уязвимее (что в будущем может привести к возникновению шантажа), и учитывать вероятность корыстных личных целей для осуществления работы персонала предприятия. Помимо всего прочего, важно постоянно рассматривать и изучать возникшие в рабочем коллективе ситуации.

Второе направление содержит методику предотвращения осуществления угроз безопасности и введения санкций для виновников [8]. Следовательно, это наполнение связано с разработкой и реализацией следующих кадровых мер:

1) проведение специальных тренингов и семинаров, направленных на обучение сотрудников обеспечивать сохранность личной и корпоративной безопасности;

2) обеспечение защиты и сохранности внутрикорпоративных данных и конфиденциальных сведений, чтобы данная информация не смогла попасть в руки потенциальных преступников;

3) обеспечение стремления сотрудников к более лояльному и более ответственному поведению на своей должности в предприятии;

4) обеспечение защищённости организации от нелояльных и ненадежных работников, которое предполагает проведение комплекса мер, направленных на оценку лояльности и благонадежности сотрудника, а также увеличение его степени, и предотвращение иного поведения сотрудников, и вдобавок введение дисциплинарных мер по отношению к таким работникам [14];

5) проведение превентивных бесед с работодателем для предупреждения возникновения конфликтных ситуаций с работниками;

6) осуществление помощи работникам, находящимся в трудной жизненной ситуации, включающей в себя оказание социальной и материальной помощи таким работникам;

7) введение специальных санкций для определённых отдельных работников в наказание за нарушение предписаний и правил собственности, информации, интеллектуальной безопасности руководителя. Такие санкции можно классифицировать как административные, экономические или социальные.

Важно отдельно отметить, что нынешних реалиях в условиях пандемии кадровая безопасность - это то, в чем особенно остро нуждается каждое предприятие, поскольку они стали более уязвимыми.

В условиях пандемии роль грамотных менеджеров повысилась в результате качественных изменений характера управления персонала вследствие повышения его социальнопсихологической составляющей. Менеджер призван обеспечивать кадровую безопасность, направленную на минимизацию кадровых угроз безопасности и со стороны сотрудников, и по отношению к ним; сокращение ущерба, возникшего вследствие пандемии; приспособление к новым социально-экономическим реалиям за счёт улучшения качества управления кадрами. Как известно, успешность фирм достигается благодаря компетентным руководителям. В руках топ-менеджеров находятся большие объемы информации, поскольку их работа в первую очередь предполагает принятие управленческих решений и разработку тактических и стратегических планов. И поэтому в нынешних условиях пандемии значительно возрастает цена ошибок и просчётов, а результативное и эффективное управление бизнесом все больше обуславливается наличием профессионализма, компетентности, опытности, деловых и личных качеств менеджеров любого уровня [3].

Довольно большой вес для обеспеченности безопасности и защиты кадров имеет принятие мер, которые были бы направлены на сокращение уровня тревожности с помощью установления открытого диалога с топ-менеджером о текущем положении организации в условиях пандемии и определения надёжных перспектив будущего взаимодействия и руководства.

Как показала практика, безопасность персонала организации может зависеть не столько от квалификационных навыков руководителей различных уровней, сколько от их личных качеств и набора ценностей, которых они придерживаются. 
Поэтому к вопросу формирования штата работников каждому работодателю нужно подходить с особой серьёзностью, чтобы его сотрудники имели гибкие навыки, стремились к самосовершенствованию и в условиях кризиса могли быстро адаптироваться и действовать с холодной головой.

\section{3. Выводы}

Таким образом, для того чтобы свести к минимуму вероятные потери фирмы в результате неэффективной кадровой безопасности, в первую очередь, нужно направить силы на разработку и внедрение профилактических мероприятий, а также реализацию мер быстрого реагирова-

Литература

1. Байнова, М. А. Анализ бизнес-процессов для идентификаџии рисков в организации // Материаль Афанасьевских чтений. 2018. № 4 (26). - URL : https://cyberleninka.ru/article/n/analiz-biznes-protsessov-dlyaidentifikatsii-riskov-v-organizatsii.

2. Волобуева, Д. В. Актуальные вопросы экономической безопасности // Молодой ученый. 2016. № 9.2. C.16-18. - URL : https://moluch.ru/archive/113/29141/.

3. Действия HR в ситуаџии пандемии [Электронный ресурс] - URL : https://assets.kpmg/content/dam/ kpmg/ru/pdf/2020/04/ru-ru-hr-actions-in-pandemic.pdf.

4. Джабраилов, М. А. Кадровая безопасность организачии как объект управления // Сочиальноэкономические явления и процессы. 2016. № 4. C. 36-40. - URL : https://cyberleninka.ru/article/n/ kadrovaya-bezopasnost-organizatsii-kak-obekt-upravleniya.

5. Замбржиикая, Е. С. Кадровый потенииал в системе управления и анализа эффективности деятельности организаџии : монография / Е.С. Замбржиџкая, Н.Е. Иванова, М.В. Павлухина. - Магнитогорск: Изд-во Магнитогорск. гос. техн. ун-та им. Г.И. Носова, 2017. - URL : https://elibrary.ru/item.asp? $i d=32754560$.

6. Крохичева, Г. Е. Кадровая безопасность в системе экономической безопасности // Интернетжурнал Науковедение. 2016. № 3 (34). C. 1-10. - URL : https://cyberleninka.ru/article/n/kadrovayabezopasnost-v-sisteme-ekonomicheskoy-bezopasnosti.

7. Кузнецова, Н. В., Тимофеева, А. Ю. Проблемы и инструментарий выявления угроз кадровой безопасности региона // Экономика региона. 2016. T. 12. № 4. C. 1123-1134. - URL : https://cyberleninka.ru/ article/n/problemy-i-instrumentariy-vyyavleniya-ugroz-kadrovoy-bezopasnosti-regiona.

8. Тимофеева, А. Ю. Факторы угроз кадровой безопасности организачии // Вестник ВолГУ. Серия 3: Экономика. Экология, 2017. № 1 (38). C. 88-96. - URL : https://cyberleninka.ru/article/n/faktory-ugrozkadrovoy-bezopasnosti-organizatsii.

9. Романцова, О. Н. Персонал как главный ресурс любой организациии / О. Н. Романцова // Молодой ученый. 2020. № 18 (308). C. 135-138. - URL : https://moluch.ru/archive/308/69450/.

10. Соломанидина, Т. О. Кадровая безопасность компании / Т.О. Соломанидина, В.Г. Соломанидин. - М. : Изд-во «Альфа-Пресс», 2016.

11. Фурсов, В. А., Лазарева, Н. В., Кущ, Е. Н., Аветова, К. Г. Кадровая безопасность предприятия : подходы, диагностика, направления совершенствования // Вестник Алтайской академии экономики и права. 2020. № 4-2. C. 270-276. - URL : http://vaael.ru/ru/article/view?id=1083.

12. Biesenthal, C., Clegg, S., Mahalingam, A., \& Sankaran, S. Applying institutional theories to managing megaprojects // International Journal of Project Management. 2018. No. 36(1). P. 43-54. - URL: https:// doi.org/10.1016/j.ijproman.2017.06.00.

13. Ongoing personnel security // A good practice guide - Crown Copyright. 2017.

14. Rothstein, H., Borraz, O., \& Huber, M. Risk and the limits of governance : Exploring varied patterns of risk -based governance across Europe // Regulation \& Governance. 2013. No. 7(2). P. 215-235. - URL : https:// doi.org/10.1111/j.1748-5991.2012.01153.x.

\section{References:}

1. Bajnova, M. A. Analiz biznes-processov dlya identifikacii riskov v organizacii // Materialy Afanas'evskih chtenij. 2018. № 4 (26). - URL : https://cyberleninka.ru/article/n/analiz-biznes-protsessov-dlya-identifikatsiiriskov-v-organizatsii.

2. Volobueva, D. V. Aktual'nye voprosy ekonomicheskoj bezopasnosti // Molodoj uchenyj. 2016. № 9.2. S.1618. - URL : https://moluch.ru/archive/113/29141/.

3. Dejstviya HR v situacii pandemii [Elektronnyj resurs] - URL : https://assets. $\mathrm{kpmg} / \mathrm{content/dam/kpmg/ru/}$ pdf/2020/04/ru-ru-hr-actions-in-pandemic.pdf.

4. Dzhabrailov, M. A. Kadrovaya bezopasnost' organizacii kak obëkt upravleniya // Social'no-ekonomicheskie yavleniya i processy. 2016. № 4. S. 36-40. - URL : https://cyberleninka.ru/article/n/kadrovaya-bezopasnostorganizatsii-kak-obekt-upravleniya.

5. Zambrzhickaya, E. S. Kadrovyj potencial v sisteme upravleniya i analiza effektivnosti deyatel'nosti organizacii : monografiya / E.S. Zambrzhickaya, N.E. Ivanova, M.V. Pavluhina. - Magnitogorsk: Izd-vo Magnitogorsk. gos. tekhn. un-ta im. G.I. Nosova, 2017. - URL : https://elibrary.ru/item.asp?id=32754560.

6. Krohicheva, G. E. Kadrovaya bezopasnost'v sisteme ekonomicheskoj bezopasnosti // Internet-zhurnal Naukovedenie. 2016. № 3 (34). S. 1-10. - URL : https://cyberleninka.ru/article/n/kadrovaya-bezopasnost-v-sisteme -ekonomicheskoy-bezopasnosti.

7. Kuznecova, N. V., Timofeeva, A. YU. Problemy i instrumentarij vyyavleniya ugroz kadrovoj bezopasnosti 
regiona // Ekonomika regiona. 2016. T. 12. № 4. S. 1123-1134. - URL : https://cyberleninka.ru/article/n/ problemy-i-instrumentariy-vyyavleniya-ugroz-kadrovoy-bezopasnosti-regiona.

8. Timofeeva, A. YU. Faktory ugroz kadrovoj bezopasnosti organizacii // Vestnik VolGU. Seriya 3: Ekonomika. Ekologiya, 2017. № 1 (38). S. 88-96. - URL : https://cyberleninka.ru/article/n/faktory-ugroz-kadrovoybezopasnosti-organizatsii.

9. Romancova, O. N. Personal kak glavnyj resurs lyuboj organizacii / O. N. Romancova // Molodoj uchenyj. 2020. № 18 (308). S. 135-138. - URL : https://moluch.ru/archive/308/69450/.

10. Solomanidina, T. O. Kadrovaya bezopasnost' kompanii / T.O. Solomanidina, V.G. Solomanidin. - M. : Izdvo «Al'fa-Press», 2016.

11. Fursov, V. A., Lazareva, N. V., Kushch, E. N., Avetova, K. G. Kadrovaya bezopasnost' predpriyatiya : podhody, diagnostika, napravleniya sovershenstvovaniya // Vestnik Altajskoj akademii ekonomiki i prava. 2020. № 4-2. S. 270-276. - URL : http://vaael.ru/ru/article/view?id=1083.

12. Biesenthal, C., Clegg, S., Mahalingam, A., \& Sankaran, S. Applying institutional theories to managing megaprojects // International Journal of Project Management. 2018. No. 36(1). P. 43-54. - URL : https:// doi.org/10.1016/j.ijproman.2017.06.00.

13. Ongoing personnel security // A good practice guide - Crown Copyright. 2017.

14. Rothstein, H., Borraz, O., \& Huber, M. Risk and the limits of governance : Exploring varied patterns of risk -based governance across Europe // Regulation \& Governance. 2013. No. 7(2). P. 215-235. - URL : https:// doi.org/10.1111/j.1748-5991.2012.01153.x. 